\title{
Imagining Geographies, Mapping Identities
}

\author{
Matthew Graves, Aix-Marseille Université \\ Elizabeth Rechniewski, University of Sydney
}

The ambition of this issue of Portal Journal of Multidisciplinary International Studies is to reach across the methodological boundaries of history, politics, literature and geography to apply their complementary perspectives to the study of identity and its relation to space and place, an aim that involves attempting to identify the many different ways the notoriously slippery concepts of identity and geography may intersect.

In the course of the twentieth century the centrifugal forces of decolonization and globalization eroded frontiers and seemed to threaten the dissolution of national and cultural identity in supranational spaces of uncertain form (European enlargement), while the centrifugal forces of resurgent regionalism raised fears of the break-up of the sovereign body of the nation. The nation-states attempted to fill the identity void by devising new forms of territorial politics (devolution, shared sovereignty) based on a reconfiguration of the foundational spaces and places or the reinvention of collective myths; at the same time, movements of resistance formed around an essentialist rereading of national space (resurgent nationalisms), while others attempted to find an alternative sense of collective belonging outside of the national framework (region, community, network). In an age of hyper-communication, the postmodern diasporas have become a source of 'long-distance nationalism' (Schiller \& Fouron 2001). 
Such geographical identities and 'the struggle over geography' (Saïd 1993: 6) ${ }^{1}$ that they imply provide the setting for a new imaginative geography: for instance, the recurrent theme of Englishness in post-devolution literature, or the revival of the travel writing genre which marked the end of decolonization. If we accept that the nation is an ‘imagined community’ (Anderson 1991), then the new spaces of identity suggest new forms and formulations of the imaginary, a geo-narrative map yet to be drawn. In the last thirty years, the 'spatial turn' in social theory has reached beyond the boundaries of geography and its subdisciplines to encourage a focus on:

the spatiality of social life, a practical theoretical consciousness that sees the life world of being creatively located not only in the making of history but also in the construction of human geographies, the social production of space and the restless formation and reformation of geographical landscapes: social being actively emplaced in space and time in an explicitly historical and geographical contextualization. (Soja 1989: 10-11)

Moreover, the disciplinary partitions have been eroded from within as much as from without, since the 'cultural turn' in geography has encouraged the recognition that the description of space can rarely escape social, political and even ideological implications. Just as space and place have become central to social theory, so has mapping emerged as a trope of spatial thinking and analysis. From Stuart Hall's 'maps of meaning' (2003: 29) to Salman Rushdie’s 'world mapped by stories, ${ }^{2}$ the map-aslogo traces itineraries through a fragmentary world of uncertain meaning.

For this issue we have selected articles that cast a fresh perspective on two areas where identity and geography intersect: the construction of identity through the imaginative recreation of place in literature: Mapping Literary Spaces; and the study of the shifting relationships of centre and periphery, exclusion and inclusion in urban settings and geopolitical confrontations: Social and Political Peripheries. ${ }^{3}$

\section{Mapping literary spaces}

The etymology of the term 'plot' goes back to Old English when one of the meanings of 'plot' or 'plat' was a plan or map of land. That this term should have migrated to describe the narrative structure of fiction reveals the parallels that can be drawn between

\footnotetext{
${ }^{1}$ The more fully elaborated text is: 'Just as none of us is outside or beyond geography, none of us is completely free from the struggle over geography. That struggle is complex and interesting because it is not only about soldiers and cannons but also about ideas, about forms, about images and imaginings' (Saïd 1993: 6).

${ }^{2}$ The expression refers to Rushdie's multimedia archive which was purchased by Emory University and subsequently exhibited there in 2010.

${ }^{3}$ We thank Miriam Thompson for her invaluable editorial work on this issue.
} 
fictional creation and map-making; as Peter Turchi (2004: 13) writes: 'in every piece we write, we contemplate a world; and as that world would not otherwise exist, we create it even as we discover it.' Turchi pursues these parallels along two lines of argument: not only does the writer create a fictional geography and setting for their story, but the very processes of writing resemble those of the cartographer since they involve choice of perspective, forms of symbolic representation, the selection of features to foreground, the depiction of relationships, and the drawing of boundaries. And through these processes, both writer and cartographer must conjure up the illusion of creating a simulacrum of reality, establishing a relationship with the real world that convinces the reader/user not of its absolute fidelity but of its validity, its usefulness and its relevance.

The metaphor that depicts the novel as charting new territory and the writer as explorer is one of the tropes of literature. Another is the metaphor that represents life as a 'journey.' Indeed it constitutes one of the central tropes of Western literature and myth: the journey of exploration, of initiation, of trial and redemption, where the main character embarks on a voyage of discovery that is also one of self-discovery and selftransformation. In his article in this issue Charles Moseley uncovers the moral and symbolic force of the geographical narrative in one of the earliest examples, that of Mandeville's Travels, an account of the part-fabled journey of the Western narrator to the East. His travels across 'macrospace' cannot be plotted onto any modern map but the trajectory of his journey reflects the theological and historical ordering of space of the Medieval worldview, where geography is a physical representation of the sacred. Even in the secular variants of this trope, that include the picaresque novel and the bildungsroman, Geography is not simply the framework of travel, the background against which the action is played out, but an actor in the drama, confronting the hero with a series of physical trials and obstacles. As the journey unfolds, the hero moves not only through a physical landscape but also through the changing social landscapes that each stage brings. His mature self is built up through these successive encounters as the experiential and symbolic journey progresses.

It is a voyage of self-discovery but also a voyage of discovery about the world for the hero and the reader, that is to say, a vehicle for critiquing existing ideas, for undoing the prejudices of the group to which one belongs. Thus Mandeville's Travels contains within it, Moseley argues, a critical meditation and commentary on Western ideas and 
practices through the encounters with the many Others that the journey affords. Similarly, in her article for this issue, Isabelle Avila shows that Marlow, the narrator of Conrad's Heart of Darkness, is forced by the end of his journey up river to reassess the true nature of savagery and civilization, and to question the self-assured depiction of European domination on the maps of colonized Africa. As these examples suggest, while the self may be built up through journeying through space and time, it may also be disrupted, challenged indeed destroyed.

In her paper to the 'Geographies of Displacement' conference in Montpellier in June 2014, Isabelle Avila drew attention to the role of maps as lieux de mémoire that organize not only space but time as well. As the blank heart of African cartography was gradually filled over the nineteenth century, the successive versions of the map of the continent, preserved in memory, became testimony to the exploits of the British and the advance of 'civilization.' The maps, displayed in schoolrooms, furnished the 'mobilier mental des Britanniques’ over several generations, providing ‘un lieu de mémoire géographique du progrès de l'exploit humain. ${ }^{, 4}$ Her case study is a potent reminder that the development of Western cartography is closely associated with the Age of Discovery and its expansion with the imperialist project. As Toal (1996: 4) writes: 'The function of cartography was to transform seized space into legible, ordered imperial territory.' In the employ of the European colonial powers, the cartographers of empire carved up the 'blanks' and 'empty quarters' of the globe into easily assimilated geometrical figures, frequently along lines of longitude and latitude rather than the ethnic, religious, linguistic, or cultural contours of their indigenous populations, even in defiance of geographical realities. In this context, the map of empire became an instrument of 'Geography Militant,' serving a dominant epistemology in a polarized world of civilized Western Self and primitive Indigenous Other.

In her article for this issue Avila argues further, however, that the apparent simplicity of the story told by the maps, of the passage from the unknown to the known, from invisibility to transparency, was challenged by literary writers of the late nineteenth century, and notably by Joseph Conrad. Through his portrayal of the shadows that close in on Marlow's voyage into the heart of darkness, the author refuses to reduce the

\footnotetext{
${ }^{4}$ Intervention by Isabelle Avila at the 'Geographies of Displacement' Conference, held at Montpellier, France, June 2014. The maps provided 'the mental furniture of the British,' 'a geographical site of memory of the progress of human achievement.'
} 
continent to the limpid surface simplicity of the imperial maps and resists the master narrative of possession.

Challenging map narratives may involve resisting the incursion of the imperial mapmaker, as the assassination of the military cartographer Richard Bartlett at the hands of Ulstermen who 'would not have their country discovered' demonstrates (quoted in Covington 2013: 153). In the hands of marginalized communities, minorities, or regionalist movements, mapping may become an instrument with which to reconquer life spaces that have been denied or confiscated. Cartographies of opposition and resistance to the abstract spaces imposed by the nation-state produce 'counter space’ (Lefebvre 1991: 383) where populations can reappropriate their cultural identities and social or political autonomy.

In the struggle over geography, counter space is typically carved out on the periphery of political societies, or at the local and regional sub-scales. In her contribution to this issue, Daniela Rogobete looks at how postcolonial literature maps out such space, diachronically as much as synchronically, creating alternative narratives of identity. In particular, she examines the claims and counter-claims made for the Indian English Novel: in achieving global recognition for Indian literature and culture while resisting the cultural compression of globalization, but also in projecting Indian identities on Western models to the detriment of regional literatures and languages. Rogobete suggests that the tensions inherent in the paradigm of the 'global novel' may be resolved with the contemporary emergence of a 'glocal' Indian literature which assimilates English and regional languages in a hybrid and eclectic genre that preserves the authenticity and diversity of cultural identities.

\section{Social and political peripheries}

The relationship of core and periphery and its related pairs, inclusion and exclusion, centre and margin, can be conceptualized in many different ways and shown to operate in many settings, affecting individuals, communities, or whole populations, as the articles in this section illustrate.

Social and political exclusion are so often symbolized through, realized in and reinforced by, spatial segregation. This is poignantly illustrated in Esme Cleall's article, Silencing deafness, which describes the increased institutionalization of people with 
disabilities, including deaf people, within asylums and residential schools in the nineteenth century. In a move not dissimilar to what Foucault named the 'Great Confinement' of the 'insane,' the deaf were increasingly segregated from 'normal' society, hidden away behind the forbidding walls of Victorian institutional architecture they were out of sight and out of mind. Boarding schools offered families of deaf children the opportunity to send away, and possibly forget, the 'problem' of disability, at least on an everyday basis. Day schools for deaf children ensured that the deaf were educated separately and differently from hearing children. Physical segregation symbolized and reinforced the marginalization of the disabled.

We could cite, too, the powerful forms of contemporary exclusion that result from urban segregation, with notable examples in current debate the social and physical isolation of the banlieues around French towns and cities. Cut off from the urban centres by poor public transport and the physical obstacles of autoroutes and ring roads, they perpetuate a cycle of exclusion, poverty, prejudice and marginalization. But perhaps the most prominent discussions around this issue in recent years have addressed broader, even existential concerns: whether the individual has been 'displaced' from modern life, uprooted and exiled from space and meaningful place. For if individual identity is rooted in place, the twentieth century saw the undermining of the frameworks that provided a stable context for the Self. The multiple dislocations of the modern world demand new ways of understanding our relationship to space, a new 'poetics of geography: a site for investigating the metaphors and narrative strategies that we use to talk about space’ according to Patricia Yaeger (1996: 5).

Much has been written over recent decades about the potential effects of the hyper refashioning of our environment, the acceleration of change and the compression of space and time that result from new technologies of travel and communication. The concept of 'non-places' (Augé 2009) problematizes the attachment to place of the contemporary citizen, condemned to inhabit the soulless environments of modern cities: has the modern world, with its standardized shopping malls and hotels, its global brands, its ceaseless redevelopments, undermined our sense of place, creating rootless populations with no attachment to their locality? The 'post-modern thesis' argues the depthlessness of attachment, the creation of a fragmented self without fixed points of reference suffering from 'ontological insecurity.' 
Others have argued that while it is true that identity in the modern world is increasingly loosened from all territorial ties, new landscapes of belonging are created: Arjun Appadurai, describing the creation through technological ties of networks uniting world-wide diaspora, writes of the 'ethnospaces' that unite people scattered across continents:

\begin{abstract}
As groups migrate, regroup in new locations, reconstruct their histories and reconfigure their ethnic projects, the ethnic in ethnography takes on a slippery, nonlocalized quality ... The landscapes of group identity — the ethnoscapes - around the world are no longer familiar anthropological objects, insofar as groups are no longer tightly territorialized, spatially bounded, historically unselfconscious or culturally homogeneous. (1996: 48)
\end{abstract}

We need perhaps, moreover, to question the often implicit assumption of the 'dislocation thesis,' that there existed an unproblematic link between place and identity that characterized past generations, an idea that is sometimes reproduced even in academic theories that contrast the complex and shifting identities of the present with some golden past of identity rooted in place, and imply or extol the necessity for a return to 'supposedly unalienated direct sensory interaction with nature’ (Appadurai 1996: 48). David Harvey (2009: 187) argues that such theories 'cannot avoid descending into a pervasive elitism,' as they contrast the empty and soulless lives of the majority with the 'authenticity' of those who live 'simple lives close to the land.'

Countering the perceived rootlessness of modern life, is the resistance of city dwellers to the juggernaut of change: for example, as Carolyn Stott's article shows, the residents who took up the defence of 'old' Belleville, continue to display a strong sense of community centred round preservation and celebration of the 'uniqueness' of this quartier of Paris. Their campaign illustrates how ideas about a locality can determine the destruction or preservation of its physical features: the historical representations of Belleville that Stott identifies draw to the area a certain type of resident, artists, writers and multiculturels, who value its unique heritage and are inspired to try to preserve and recreate (or create?) the qualities it possesses in reputation.

Stott reveals too the power of imaginary boundaries: the quartier known as 'Belleville' overflows and transgresses its current administrative boundaries: it is a palimpsest of layer upon layer of historical associations and literary representations that overlap but never quite coincide. Not only does the area defy any attempt to impose on it clear boundaries but internally it is criss-crossed by divisions and contrasts defined by the 
needs, priorities and practices of the various communities who live there: high and low Belleville; the old streets with their small workers' cottages transformed into studios and the grand towers of the HLM; the sudden transformations from one street to another as the ethnic mix of each sector shifts. Today's inhabitants impose on it their own meanings through their social and work activities: the artists who see the area as redolent with an atmosphere propitious to their creativity and lifestyle; the transplantés who relate to it in utilitarian terms mainly as a cheaper place to live; immigrants who, benefitting from the quartier's reputation for tolerance of diversity, seek to reproduce the familiarity of home in the streets and markets creating 'microterritoires,' 'dans lequel les communautés diasporiques cherchent un ancrage territorial' (Bruneau 2006: 328). The tourists create yet another Belleville organized around their visits to landmarks and historic sites: the Père Lachaise cemetery, the Parc de Belleville; or they follow the trail of Daniel Pennac's famous fictional Mallaussène family. Each group, and indeed each inhabitant, creates their own places out of the space known as Belleville (which no longer exists on any map), in a dialectical relationship where representation interacts with expectation and informs practice. In Henri Lefebvre's terms, the quartier is 'imagined, perceived and experienced as spaces of representation, representations of space and spaces of social practice at one and the same time' (Holloway \& Hubbard 2000: 236).

Annie Ousset-Krief brings to life another popular area of a great city: the lower East Side of New York whose identity and architecture were transformed in the late nineteenth century by the influx of a vibrant community of Jews. Like Stott's study of Belleville, Ousset-Krief's portrait of the lower East Side describes the transformations that the area has undergone over the centuries as first home to successive waves of poor migrants. Hundreds of thousands of Jews, often escaping from pogroms in Russia and Eastern Europe, emigrated, along with Italians and many other nationalities, to America at the end of the nineteenth century; many thousands of Jews settled in the teeming East Side tenements and tried to recreate a sense of home by re-establishing the structures that had governed their lives in the shtetl: worship, education. Ousset-Krief details the architectural legacy left by their investment in this new territory while demonstrating that the significance of these material traces of the past reaches beyond the architectural to represent a link with past lives, with the 'origins' of the Jewish community in the USA; they offer a traceable lineage to the place where their grandparents and great- 
grandparents first settled. Indeed walking tours are organized to allow descendants to follow literally in their footsteps. While more recent populations of immigrants have long replaced the majority of Jews, the Jewish community's attachment to this, their first 'home' in the USA, remains strong and offers them a site of belonging that may displace the sense of loss stemming from their forced separation from their traditional homelands in Eastern Europe.

Colonial populations too, remote from the metropolitan centre, may be condemned by the tyranny of distance never to see the home country to which they nevertheless feel they belong. Such was the fate of the Australian colonists in the nineteenth century who found themselves at the edge of the known world, on the periphery of Britain's empire, just as New Caledonia was a remote and insignificant possession of the French empire, au bout du monde. The case of the relationship between Australia and New Caledonia and their metropoles in the nineteenth century illustrates however the ambiguity and fluidity of definitions of centre and periphery. As Elizabeth Rechniewski shows in this issue, Australia and New Caledonia, far-flung outposts of the British and French empires on the geographical periphery and political margins of their metropolitan masters, were nevertheless fatally caught up in events that happened thousands of kilometres away, as the shifting alliances between the imperial powers were refracted in the relationships between their colonies. And Australia and New Caledonia formed in themselves a centre-periphery nucleus, bound together through their common European origins and settler colonialism but in an unequal relationship: Australia the much larger, richer and longer established colony dominating trade and investment in New Caledonia. Yet for much of the nineteenth and early twentieth century, Australia feared its much smaller and weaker neighbour as a threat to her very existence, as a steppingstone for French and later Japanese aggression.

Gerard Toal (1996: 1) has written that geography is not a noun but a verb: it does not describe what space is but studies what we do with space, imaginatively and politically. The articles in this issue illustrate the exercise of the literary and political imagination and the role of materiality and memory in the creation of geographic representation. They show too a new awareness of the centrality of space in the constitution of identities, and the need for a new geocritical reading of its discourse, as the 
interrelations of place and community are played out on the many scales of social and political life, from the local to the global.

\section{Reference List}

Anderson, B. 1991, Imagined Communities: Reflections on the Origin and Spread of Nationalism, $2^{\text {nd }}$ ed. Verso, London.

Appadurai, A. 1996, Modernity At Large: Cultural Dimensions of Globalization. University of Minnesota Press, Minneapolis.

Augé, M. 2009, Non-Places: An Introduction to Super Modernity. $2^{\text {nd }}$ ed., (trans.) J. Howe. Verso, London.

Bruneau, M. 2006, 'Les territoires de l'identité et la mémoire collective en diaspora,' L'Espace géographique, vol. 35, no. 4: 328-333.

Cosgrove, D. 2004, 'Landscape and Landschaft: Lecture delivered at the "Spatial Turn in History" Symposium at the German Historical Institute, February 19, 2004,' GHI bulletin, vol. 35, Fall: 5771.

Covington, S. 2013, “"The Odious Demon from Across the Sea.” Oliver Cromwell, Memory and the Dislocations of Ireland,' in Memory before Modernity: Practices of Memory in Early Modern Europe, (eds) E. Kuijpers, J. Pollmann, J. Mueller \& J. van der Steen. Koninklijke Brill NV, Leiden: 149-164.

Daniels, S. 1993, Fields of Vision: Landscape Imagery and National Identity in England and the United States. Polity Press, Cambridge.

Delaney, D. 2005, Territory: A Short Introduction. Blackwell, Oxford. doi: http://dx.doi.org/10.1002/9780470773925

Hall, S. 2003, Representation: Cultural Representation and Signifying Practices. Sage Publications/The Open University, London.

Harvey, D. 2009, Cosmopolitanism and the Geographies of Freedom. Columbia University Press, New York.

Holloway, L. \& Hubbard, P. 2000, People and Place: The Extraordinary Geographies of Everyday Life. Prentice Hall, New York.

Lefebvre, H. 1991, The production of space. Wiley-Blackwell, London.

Saïd, E. 1993, Culture and Imperialism. Vintage, London.

Schiller, N. G. \& Fouron, G. E. 2001, Georges Woke up Laughing: Long-Distance Nationalism and the Search for Home. Duke University Press, Durham, NC, \& London.

Soja, E. 1989, Postmodern Geographies: The Reassertion of Space in Critical Social Theory. Verso, London.

Toal, G. 1996, Critical Geopolitics: The Politics of Writing Global Space. University of Minnesota Press, Minneapolis.

Turchi, P. 2004, Maps of the Imagination: the Writer as Cartographer. Trinity University Press, San Antonio, Texas.

Yaeger, P. 1996, The Geography of Identity. University of Michigan Press, Ann Arbor. 